\section{Changes in Fractional Exhaled Nitric Oxide Levels After Bronchial Challenge With Aspirin in Patients With Aspirin-Induced Asthma}

Sánchez-Jareño $\mathrm{M}^{1}$, Barranco $\mathrm{P}^{1,2}$, Padial Vilchez $\mathrm{MA}^{3}$, Valbuena $\mathrm{T}^{3}$, Lluch $\mathrm{M}^{1}$, Domínguez-Ortega $\mathrm{J}^{1,2}$, López-Carrasco $\mathrm{V}^{1}$, Quirce $\mathrm{S}^{1,2}$

${ }^{I}$ Servicio de Alergología, Hospital Universitario La Paz, IdiPAZ, Madrid, Spain

${ }^{2}$ CIBERES, Madrid, Spain

${ }^{3}$ Servicio de Alergología, Hospital Infanta Sofia, San Sebastián de los Reyes, Madrid, Spain

J Investig Allergol Clin Immunol 2019; Vol. 29(2): 137-139 doi: $10.18176 /$ jiaci.0344

Key words: AERD. FeNO. Bronchial challenge. Phenotypes.

Palabras clave: EREA. FeNo. Provocación bronquial. Fenotipos.

Aspirin-exacerbated respiratory disease (AERD) affects patients with asthma, chronic rhinosinusitis (CRS), and nasal polyposis with airway reactions following the ingestion of nonsteroidal anti-inflammatory drugs (NSAIDs) [1]. Bronchial challenge with lysine-acetylsalicylate (L-ASA) is a safer diagnostic method for aspirin-induced asthma (AIA) than oral challenge, although it is less sensitive [2]. Fractional exhaled nitric oxide (FeNO) is a marker of type 2-driven inflammatory mechanisms in the airway [3]. The association between changes in FeNO levels and exposure to NSAIDs in specific bronchial challenge has not been well characterized. The aim of this study was to evaluate changes in FeNO levels after bronchial challenge with L-ASA in patients suspected of having AIA. The local ethics committee approved the study, and all patients gave their written informed consent (PI-2860).

Asthmatic patients aged $\geq 18$ years with symptoms of AIA evaluated at the Allergy Department of University Hospital La Paz, Madrid, Spain from 2009 to 2016 were included. FeNO was measured using a portable nitric oxide (NO) analyzer (NioxMinoTM, Aerocrine) immediately before the bronchial challenge (baseline FeNO/FeNOpre) and 24 hours after L-ASA challenge (FeNOpost). The increase in FeNO levels was calculated by subtracting FeNOpre from FeNOpost. Baseline FeNO $<40$ ppb was considered normal [3]. Bronchial challenge with L-ASA was performed using an electronic dosimeter (Spire Elektro, Respiratory Care Center) following previously published protocols $[2,4]$, according to which increasing doses of L-ASA were inhaled every 30 minutes up to a maximum accumulated dose of $127.9 \mathrm{mg}$. A provocative dose causing a $20 \%$ fall in baseline fractional exhaled volume in the first second $\left(\mathrm{FEV}_{1}\right)\left(\mathrm{PD}_{20}\right)$ was calculated based on linear interpolation between points on the log dose-response curve. Bronchial challenge was considered to be positive in the case of an early response in the form of a drop in $\mathrm{FEV}_{1} \geq 20 \%$, a prolonged early asthmatic response, and a dual response or late asthmatic response. Bronchial challenge was negative
Table. Characteristics of the Study Population

\begin{tabular}{|c|c|c|}
\hline & $\begin{array}{c}\text { AIA } \\
\text { (Positive BC } \\
\text { L-ASA) }\end{array}$ & $\begin{array}{c}\text { Aspirin-Tolerant } \\
\text { Asthmatics } \\
\text { (Negative BC } \\
\text { L-ASA) }\end{array}$ \\
\hline \multicolumn{3}{|l|}{ Gender } \\
\hline Male & $9(37.5)$ & $24(47)$ \\
\hline Female & $15(32.4)$ & $27(53)$ \\
\hline Mean (SD) age & $44.42(16)$ & $41.66(16)$ \\
\hline Mean (SD) body mass index & $25(3.5)$ & $25.14(5.4)$ \\
\hline $\begin{array}{l}\text { Smoking habit, No. }(\%) \\
\text { Smoker } \\
\text { Nonsmoker }\end{array}$ & $\begin{array}{c}6(25) \\
18(75)\end{array}$ & $\begin{array}{c}9(18) \\
42(82)\end{array}$ \\
\hline $\begin{array}{l}\text { Personal history of atopy, No } \\
\text { No } \\
\text { Yes }\end{array}$ & $\begin{array}{c}(\%) \\
14(61) \\
9(39)\end{array}$ & $\begin{array}{l}41(80) \\
10(20)\end{array}$ \\
\hline $\begin{array}{l}\text { Previous diagnosis, No. (\%) } \\
\text { Asthma } \\
\text { Asthma, rhinitis } \\
\text { Asthma, nasal polyposis }\end{array}$ & $\begin{array}{c}3(12.5) \\
7(29.1) \\
14(58.3)\end{array}$ & $\begin{array}{l}10(20) \\
26(51) \\
15(29)\end{array}$ \\
\hline $\begin{array}{l}\text { Median (IQR) baseline } \\
\text { eosinophilia }\end{array}$ & $245(3440-30)$ & $260(0-1400)$ \\
\hline \multicolumn{3}{|l|}{ Median (IQR) total IgE, kU/L } \\
\hline $\begin{array}{l}\text { Severity of asthma, No. (\%) } \\
\text { Moderate } \\
\text { Severe }\end{array}$ & $\begin{array}{l}15(62.5) \\
9(37.5)\end{array}$ & $\begin{array}{c}28(55) \\
23(45.1)\end{array}$ \\
\hline $\begin{array}{l}\text { Baseline lung function } \\
\text { FEV }_{1}, \% \text { predicted } \\
\text { FVC, \% predicted }\end{array}$ & $\begin{array}{c}97.41(19.4) \\
109.11(15)\end{array}$ & $\begin{array}{c}99(15) c ̧ \\
107(13.4)\end{array}$ \\
\hline $\begin{array}{l}\text { Median (IQR) } \\
\text { baseline FeNO, ppb }\end{array}$ & $43(11-115)$ & $27.50(9-134)$ \\
\hline $\begin{array}{l}\text { Clinical reaction NSAIDs, No } \\
\text { Cough, dyspnea, } \\
\text { wheezing (CDW) } \\
\text { Dyspnea } \\
\text { CDW + rhinitis } \\
\text { CDW + urticaria } \\
\text { Rhinitis + dyspnea }\end{array}$ & $\begin{array}{l}\text { o. }(\%) \\
\begin{array}{c}10(59) \\
1(6) \\
3(17) \\
2(12) \\
1(6)\end{array}\end{array}$ & $\begin{array}{l}15(43) \\
8(23) \\
5(14) \\
3(9) \\
4(11)\end{array}$ \\
\hline $\begin{array}{l}\text { NSAIDs involved, No. (\%) } \\
\text { Aspirin } \\
\text { Ibuprofen } \\
\text { Metamizole } \\
\text { Aspirin + other }\end{array}$ & $\begin{array}{l}7(28) \\
9(36) \\
8(32) \\
1(4)\end{array}$ & $\begin{array}{l}18(36) \\
16(32) \\
15(30) \\
1(2)\end{array}$ \\
\hline $\begin{array}{l}\text { Median (IQR) } \\
\text { PD }_{20} \text { BC L-ASA }\end{array}$ & $29(2.06-65)$ & \\
\hline $\begin{array}{l}\text { FeNO, ppb } \\
\text { Baseline } \\
24 \text { hours postchallenge }\end{array}$ & $\begin{array}{l}45.5(33.6-57.5) \\
54.5(39.6-69.5)\end{array}$ & $\begin{array}{c}37.3(29.1-45.4) \\
39(28.8-40.2)\end{array}$ \\
\hline $\begin{array}{l}\text { Incremental FeNO, ppb } \\
\quad P \text { value }\end{array}$ & $\begin{array}{l}9(2.9-15) \\
.004\end{array}$ & $\begin{array}{c}1.7(-2.4 \text { to } 5.8) \\
.409\end{array}$ \\
\hline
\end{tabular}

Abbreviations: AIA, aspirin-intolerant asthma; BC, bronchial challenge; FeNO, fractional exhaled nitric oxide; $\mathrm{FEV}_{1}$, forced expiratory volume in the first second; FVC, forced vital capacity; L-ASA, lysine-acetylsalicylate; NSAID, nonsteroidal antiinflammatory drug; $\mathrm{PD}_{20}$, provocative dose causing a $20 \%$ fall in baseline $\mathrm{FEV}_{1}$. 
if the maximum dose was reached and no drop in $\mathrm{FEV}_{1}$ or peak expiratory flow $\geq 20 \%$ was observed in the following 24 hours $[2,4]$. At the time of bronchial challenge, patients had to have withdrawn their regular treatment as per EAACI guidelines [4]. Data were analyzed using SAS v9.3 (SAS, Institute). The groups were compared using the $\chi^{2}$ test. Nonnormally distributed variables were compared using the Mann-Whitney test and multiple comparisons using the Bonferroni test. A $P$ value $\leq .05$ was considered significant.

Seventy-five patients ( $56 \%$ women) were included. Fortythree $(57 \%)$ had moderate persistent asthma, and $32(43 \%)$ had severe asthma. The clinical characteristics are listed in the Table. Twenty-four patients had a positive bronchial challenge result (32\%): 17 with an early asthmatic response, 1 with a prolonged early response, 4 with a dual response, and 2 with a late isolated response. Fifty-one patients had a negative result (68\%). Seventy-two FeNOpre and 66 FeNOpost measurements were performed. A significant increase in FeNO levels ( 9 ppb [3]) after bronchial challenge was found in patients with a positive result with L-ASA $(P=.004)$, whereas no significant increase in FeNOpost (1.7 ppb [2]) was observed in the negative bronchial challenge group $(P=.409)$. Regardless of baseline FeNO (FeNOpre $<40 \mathrm{ppb}$ and $\geq 40 \mathrm{ppb}$ ), patients with a positive bronchial challenge result experienced a significant increase in FeNO after bronchial challenge with L-ASA $(P<.001)$. This was not the case when the result of the challenge test was negative $(P=.527)$. The median (IQR) peripheral eosinophil count was $245 / \mathrm{mm}^{3}$ (30$3440)$ in positive bronchial challenge and $260 / \mathrm{mm}^{3}(0-1440)$ in negative bronchial challenge. This difference was not statistically significant. No significant differences were found for the other variables analyzed (Table).

AIA was confirmed by bronchial challenge with L-ASA in $32 \%$ of patients with a suspected clinical history of reaction to NSAIDs. This finding is in line with previous publications by our group [2]. A significant increase in FeNO levels after the L-ASA inhalation test was observed only in AIA confirmed by a positive bronchial challenge $(P=.004)$. Increases in FeNO levels after bronchial challenge with specific allergens have been reported [3]. In contrast, Jerschow et al [5] reported a decrease in FeNO levels after oral challenge with $40 \mathrm{mg}$ of aspirin. We speculate that this difference could be due to the type of challenge (oral vs bronchial) and/or the timing of measurement of FeNO levels (24 hours after challenge vs during the first hour after administration of aspirin) [5]. Moreover, the patients in the studies reported did not present a decrease in $\mathrm{FEV}_{1} \geq 20 \%$ after oral aspirin, whereas all of the challengepositive patients experienced a drop in $\mathrm{FEV}_{1} \geq 20 \%$ [5]. The only study to investigate AIA and changes in NO levels after challenge with L-ASA was performed in 2009 by Rolla et al [6], who determined whether inhalation of L-ASA could affect FeNO levels in patients with previously confirmed AERD. The study included only 20 mild asthmatic patients and 10 nonasthmatic patients as a control group, in contrast with the 75 asthmatic patients (43 with moderate persistent asthma and 32 with severe asthma) included in the present study. Similarly, Rolla et al obtained a significant increase in FeNOpost only in the challenge-positive group $(P<.001)$. FeNOpre levels were similar in both studies (29.5 ppb). The increase in FeNOpost levels we observed ( $9 \mathrm{ppb}$ ) was lower than that reported by Rolla et al and can be explained by the heterogeneous clinical characteristics of patients included in both studies. For example, $89 \%$ of the patients were diagnosed with CRS and/or nasal polyposis compared with the $33.3 \%$ prevalence of rhinitis. The authors reported a significant correlation between the increase in sputum eosinophils and the increase in FeNO in AIA patients after inhalation of L-ASA as an indicator of a type 2 inflammatory phenotype [6]. In recent decades, IL-13 has proven to be an inflammatory cytokine involved in the type 2 pathway, particularly as a key regulator in NO production and in recruitment of eosinophils in the airway [7-9]. Based on these findings, the inflammatory mechanism may explain the increase in FeNO level in AIA patients after bronchial challenge with L-ASA. Similarly, it can be hypothesized that cytokines such as IL-5, IL-4, IL-13, and even IgE play a vital role in the pathogenesis of AERD, enabling AIA patients to benefit from therapy with biologics [7-10].

To the best of our knowledge, we report the first large sample of patients with severe and moderate asthma in whom changes in FeNO levels after bronchial challenge with L-ASA have been evaluated.

\section{Acknowledgments}

The authors would like to thank Rosario Madero for the statistical analysis.

\section{Funding}

The authors declare that no funding was received for the present study.

\section{Conflicts of Interest}

The authors declare that they have no conflicts of interest.

\section{References}

1. Laidlaw TM, Boyce JA. Aspirin-Exacerbated Respiratory Disease-New Prime Suspects. N Engl J Med. 2016;374:484-8.

2. Barranco P, Bobolea I, Larco Jl, Prior N, López-Serrano MC, Quirce S. Diagnosis of aspirin-induced asthma combining the bronchial and the oral challenge tests: a pilot study. J Investig Allergol Clin Immunol. 2009; 19:446-52.

3. Pedrosa M, Barranco P, López-Carrasco V, Quirce S. Changes in exhaled nitric oxide levels after bronchial allergen challenge. Lung. 2012;190:209-14.

4. Nizankowska-Mogilnicka E, Bochenek G, Mastalerz L, Swierczyńska M, Picado C, Scadding G, et al. EAACI/GA2LEN guideline: aspirin provocation tests for diagnosis of aspirin hypersensitivity. Allergy. 2007;62:1111-8.

5. Jerschow E, Ren Z, Hudes G, Sanak M, Morales E, Schuster V, et al. Utility of low-dose oral aspirin challenges for diagnosis of aspirin-exacerbated respiratory disease. Ann Allergy Asthma Immunol. 2016;116:321-8.

6. Rolla G, Di Emanuele A, Dutto L, Marsico P, Nebiolo F, Corradi $F$, et al. Effect of inhalation aspirin challenge on exhaled nitric oxide in patients with aspirin-inducible asthma. Allergy. 2004;59:827-32. 
7. Bagnasco $D$, Ferrando $M$, Varricchi $G$, Passalacqua $G$, Canonica GW. A Critical Evaluation of Anti-IL-13 and AntiIL-4 Strategies in Severe Asthma. Int Arch Allergy Immunol. 2016;170:122-31.

8. Sastre J, Dávila I. Dupilumab: A New Paradigm for the Treatment of Allergic Diseases. J Invest Allergol Clin Immunol. 2018;28:139-50.

9. Kim $H_{1}$, Ellis AK, Fischer $D$, Noseworthy $M$, Olivenstein $R$, Chapman KR, et al. Asthma biomarkers in the age of biologics. Allergy Asthma Clin Immunol. 2017;17:13-48.

10. Phillips-Angles E, Barranco $P$, Lluch-Bernal M, DominguezOrtega J, López-Carrasco V, Quirce S. Aspirin tolerance in patients with nonsteroidal anti-inflammatory drugexacerbated respiratory disease following treatment with omalizumab. J Allergy Clin Immunol Pract. 2017;5:842-84.

1. Manuscript received August 30, 2018; accepted for publication October 21, 2019.

Marta Sánchez-Jareño

Allergy Department, Hospital Universitario La Paz E-mail: martasanchezjare@gmail.com 